\title{
Cartografia da cena contemporânea: matrizes teóricas e interculturalidade
}

\author{
Renato Cohen
}

"Se partires um dia ao Guararavacã do Guaicuí,

faz votos de que o caminho seja longo, repleto de aventuras, repleto de saber... nem Minotauros nem Medusas nem a escuridão te intimidem;..

Tem todo o tempo Guararavacã do Guaicuí na mente.

Faz votos que o Caminho seja longo. Estás predestinado a ali chegar.

Mas não apresses a viagem nunca”.

(Hibridismo entre o original Ítaca, de Konstantinos Kavafis e a obra de Guimarães Rosa.)

\section{A cena cultural contemporânea: um topos transcultural}

)

ode-se falar no estatuto de um teatro contemporâneo brasileiro que se consolida nos anos 80 e 90, formalizando uma cena demarcada por novas escrituras que incorporam a dramaturgia de processo, as hibridizaçôes entre textualidades, imagens e acon- tecimentos, pela atuação performática e pela veiculação de multimídia e de novas tecnologias. Essa nova teatralidade insemina-se num topos transcultural que presentifica os dialogismos entre signos regionais e universais, entre um suposto "centro" primário de cultura e suas periferias, entre culturas consagradas e suas bordas.

As recentes manifestaçôes da cena, das literaturas e da dança-teatro brasileira, criam o contorno de expressões e eventos que estão, sobretudo, alinhados à uma cultura e zeitgeist contemporâneos ${ }^{1}$ demarcados por uma re-territorialização, pelos deslocamentos e pela recontextualização dos conteúdos, com predominância de cartografias que privilegiem a espacialização antes que a temporalidade.

Situando-se numa topografia predominantemente urbana, não cronotópica, constituída por territórios (sites) universais, a cena contemporânea alude a imagens, fluxos, textos e ícones que configuram um topos pós-industrial (pós-moderno) que pode ser situado em Nova York, São Paulo, Berlim ou em qualquer outra pólis moderna. Um espaço, ao mesmo tempo

Renato Cohen é artista e pesquisador, com investigação nas artes da performance e suas mediações com tecnologia. Como pesquisador, participa como professor do Programa de Comunicação e Semiótica da PUC-SP onde coordena o Núcleo de Estudos da Performance. É autor de Performance como linguagem (1987) e Work in Progress na cena contemporânea (Ed. Perspectiva, 1998).

1 Espírito de época. Utilizo o termo romântico para referenciar o contemporâneo (Cohen, 1998, p. xxiii). 
real e ficcional, que transita tanto pelo topos do "não lugar", nomeado por Pierre Lévy $(1998)^{2}$ e apropriado tanto pela publicidade quanto pelo espaço cibercultural, das redes, da universalidade, da cidadania.

Essa cena demarca as passagens contemporâneas do texto ao hipertexto, da interpretação à performance, do corpo físico, em presença, às suas virtualidades, das hibridizaçóes e desdobramentos textuais, pressupondo polimorfismo de conteúdos e de qualidades cênicas, das ambigüidades, polissemias de prismas e de recepçôes. Esta cena é visível nas montagens dos brasileiros Bia Lessa, Gerald Thomas, Enrique Diaz, para citar alguns, nas encenações multimidiáticas dos norte-americanos Wooster Group e Richard Foreman, nas escrituras intertextuais de Robert Wilson e de Heiner Muller.

A cena contemporânea já supera os impasses da Pós-Modernidade, e se sustenta nas intensidades, nas linhas de subjetivação que incorporam a multiplicidade, nas várias vozes envolvidas nas ações e, também, como linguagem, na legitimação do fragmentário, do informe, do assimétrico. Há, sobretudo, uma busca de experimentação e de vivificação que é parelha dos novos estatutos da ciência, da relatividade, da visão de corpos e campos dinâmicos, que se estabelecem criando novos contornos para o real.

Dentro dessa nova ordem a teatralidade contemporânea contrapóe-se a um teatro moderno assentado nos gêneros, na interpretação psicológica naturalista, na presença a priori de um dramaturgo-autor, de um diretor-encenador, de um ator-intérprete, de contextos demarcados da cena. Teatro este que é herdeiro do aristotelismo e de suas atualizaçóes pressupostas por Stanislavski e mesmo por seus antípodas nas figuras de Meyerhold, do teatro político brechtiano, da cena modernista de Pirandello e Lorca, dos primeiros textos de Beckett, para citar al- guns. Uma cena assentada nas dramaturgias, num logos manifestado pela encenação, pelas continuidades, pelos espaços da representação.

No mundo contemporâneo impõe-se sobre os modelos de unidade e lógica de ações dramáticas, do apogeu e da catarse, e de suas atualizações do século XIX - com a Gesamtkunstwerk (obra de arte total), proposta por Richard Wagner, ou a poética cênica de Gordon Craig (que buscam afinal uma unidade através da presença de um criador-atuante) - um modelo de justaposição. Este modelo é amplificado pelas tecnologias em que se operacionalizam os fragmentos, a emissão múltipla, o texto ideogramático, os procedimentos de collage, montagem e mediação ${ }^{3}$.

As textualidades contemporâneas são assentadas na polifonia, na hibridização, na deformação: nas intertextualidades entre a palavra, as materialidades e as imagens, nas formas antes que nos sentidos, nas poéticas desejantes que dão vazão às corporalidades, às expressões do sujeito nas paisagens do inconsciente e em suas mitologias primordiais. É uma cena que é tributária da perspectiva cubista, das vanguardas, das experimentações da arte-performance em todas as suas derivações, e dos desdobramentos e vivências de cada uma desta "tradiçôes". É o momento conjuntivo de Deleuze, disso e daquilo, duma cena que dá conta da multiplicidade em seu conjunto de manifestaçôes, espetáculos e acontecimentos.

O encenador Antonio Araújo cria em $A$ pocalipse 1.11, por exemplo, planos intertextuais, hibridizando as mitopoéticas bíblicas e a voz dos despossuídos e marginalizados brasileiros. Numa textualidade construída em work in progress por Fernando Bonassi, que incorpora a dramaturgia dos atores, funde ficção e planos de realidade, as ambigüidades entre o espaço mítico e o espaço destronado de uma penitenciária.

2 Terminologia formulada por Marc Augé (Antropologia da Supermodernidade, 1998).

3 Ver Silvia Fernandes (Memória e invenção: Gerald Thomas em cena, 1998) 
Num panorama, não exaustivo, comparecem com significação a essa cena autoresencenadores como Bia Lessa (Orlando, 1997) Gerald Thomas (Nowhere Man, 1998; The Ventriloquist, 1999) Enrique Dias (A Bau A Qu, 19974; Melodrama, 1999), Gabriel Vilela, Ulisses Cruz, Márcio Aurelio e, em trabalhos mais recentes, Renato Cohen (KA, 1998; Dr. Faustus Liga à Luz, 1999), Antonio Araújo (O Livro de Jó, 1998; Apocalipse 1, 11, 1999), Dionísio Neto (Perpétua, 1998) a butoísta Maura Baiochi, Daniela Thomas, Gilberto Gawronski, Chiquinho Medeiros, entre outros artistas destacados. Teatro que tem ressonância com as experiências dos concretistas brasileiros, em suas textualidades verbivocovisuais ${ }^{5}$, com a cena dos videomakers Eder Santos, Walter Silveira e Lucila Meirelles, com a dança da Cia. de Dança Burra, com as instalaçôes performance de Aguillar e Tunga e com a musicalidade do concreto Lívio Tratemberg e do tecno-acústico Wilson Sukorski. Essa cena é também atuada por encenadores de outras geraçôes: Antunes Filho, no seu recente As Troianas (1999) intertextualiza Ésquilo com as guerras balcânicas; José Celso Martinez Correa carnavaliza e tropicaliza os clássicos em suas re-criações Ham-let (1998) e As Bacantes (1997-9).

Outra frente fundamental conjuga trabalhos de ponta que operam uma interlinguagem, e outros, nomeados num campo da "cultura das bordas" 6 incluindo-se desde a mediação tecnológica como na a exposição Imanência (Casa das Rosas, São Paulo, 1998) que dispôs oito performers, em tempo real, simul- taneamente no espaço físico do Museu e da Rede (Internet), até trabalhos cênicos com pacientes psiquiátricos, como nas montagens de Ueinzz - Viagem a Babel (1998) e Dedálus (1999) com usuários do Hospital Dia "A Casa". Nessa cartografia dos criadores é importante destacar, embora não pertençam à mesma linhagem tanto formal, quanto teórica, o trabalho de dramaturgos-encenadores como Sérgio Carvalho, Luís Alberto de Abreu, Fauzi Arap, entre outros, mais próximos dos procedimentos modernistas, com perspectiva política e culturalista.

A revolução cênica que se estabeleceu no teatro contemporâneo coloca no bojo da cena performances que criam outro diálogo com o campo dos fenômenos, sejam eles existenciais, físicos ou sociais. Essa cena, evidentemente, está influenciada pelo teatro da morte de Tadeusz Kantor, pelo teatro total, multimidiático, de Robert Wilson, que já com Life \& Times of Joseph Stalin $(1973)^{7}$ e Einstein on the Beach (1975), juntava sonoridades, tecnologia, performance, idiossincrasia e onirismo a uma visão multifacetada, equiparando paisagens visuais, textualidades, atuações, luminescências, numa cena de intensidades em que os vários procedimentos criativos trafegam sem as hierarquias clássicas texto-ator-narrativa. Está também demarcada nos planos simultâneos do discurso do Wooster Group, na escritura disjuntiva de Samuel Beckett, na dança minimal de Robert Wilson e Lucinda Childs; e, num leque mais amplo de trabalhos tão distintos como os environment plásticos de Christo - citados por

4 A partir de conto original de Jorge Luís Borges.

5 O grupo Noigrandes dos irmãos Augusto e Haroldo de Campos e Décio Pignatari.

6 Termo cunhado por Jerusa Pires Ferreira, do Núcleo de Poéticas da Oralidade, da PUC-SP, no texto Heterônimos e cultura das bordas: Rubens Luchetti (1990).

7 Essa peça, por causa de censura, foi encenada no Brasil com o título Life \& Times of Dave Clark, em cena que revolucionou o teatro brasileiro. Bob Wilson volta em 1994, na Bienal Internacional de São Paulo - em curadoria de João Cândido Galvão - com When We Dead Awaken, de Ibsen. 
Gerald Thomas -, nas epifanias visuais de Bill Violla e Gary Hill, nas corporalidades e representações espasmódicas do Tanz-Theatre de Pina Bausch, no butoh de Kazuo Ohno, de Sankai Juku e de Min Tanaka.

Também, são referenciais e fundantes o teatro primordial de Grotowski, a vertente étnica e antropológica de Peter Brook e Barba, os movimentos gerativos de Merce Cunninghan, a desconstrução sonora proposta por John Cage, as performances agônicas e conceituais de Joseph Beuys e Marina Abramovic - com sucessivas passagens no Brasil. De fato, são retomados, na gênese dessa cena, experimentos das vanguardas históricas - a forma autônoma futurista, a sonoridade dadá, a fluxo automático dos surrealistas - e da arte performance numa trajetória em que os procedimentos do formalismo, da arte conceitual, do minimalismo e da mediação vão compor as matrizes da cena contemporânea. Lúcio Agra (1997) destaca a importante replicação que as vanguardas européias vão ter no Brasil, na figura de artistas como Hélio Oiticica, Rogério Sganzela e Wally Salomão, entre outros.

Essas referências cênicas à contemporaneidade, tiveram, também, um momento gerativo original e único no Brasil, nos anos 60, em eventos organizados por Ruth Escobar, com a presença de encenadores como Victor Garcia ( $O$ Balcão, 1968) e Jerome Savary e, nas colaborações entre o Grupo Oficina de São Paulo e os grupos Los Lobos (Argentina) e Living Theatre, de Julien Beck e Judith Malina.

Em inseminaçôes próprias do movimento cultural brasileiro, desde o nomeado procedimento antropofágico - da devoração e reapropriação de conteúdos - por Oswald de Andrade, tem-se lidado, conscientemente, com as polaridades entre campos de identidade e alteridade. Como linguagem contemporânea, orquestra-se uma cena polifônica e polissêmica, apoiada na rede, e em narrativas hipertextuais que se organizam pela performance, por imagens deslocadas, por desdobramentos e não mais pela lógica aristotélica das ações, pela fabulação e por construções psicológicas de personagem. Hipertexto que aqui é definido enquanto superposição de textos incluindo conjunto de obra, textos paralelos, memórias, citação e exegese. O semiólogo russo Iuri Lotman (1997) nomeia o grande hipertexto da cultura, depositário de historiografia, memória, campo imaginativo e dos arquétipos primários.

Num imbricamento intenso entre criador-criatura-obra, a cena dá tessitura às fraturas pós-modernas, estabelecendo um continuum nas descontinuidades, permeando intensamente as ambigüidades entre arte e vida. Opera-se uma nova cena que incorpora a não seqüencialidade, a escritura disjuntiva e a emissão icônica, numa cena de simultaneidades, sincronias, superposições, amplificadora das relaçōes de sentido, dos diálogos autor-recepção, fenômeno e obra. Flora Sussekind (1995, p. 1) teorizando a cena de Gerald Thomas e Bia Lessa, fala em "corpos sem vozes, vozes sem corpo...", em procedimentos de disjunção que enfatizam a dessincronização, o corte temporal entre corpo e presença, forma e sentido.

Nascendo no contexto do pós-estruturalismo, sob a égide da desconstrução, essa cena assinala a contemplação do múltiplo, da pluralidade em contraparte ao logicismo linear aristotélico-cartesiano. Em semioses que incorporam o dialogismo com o modelo predominante propõe-se uma "Estética da Diferença" com os dispositivos rizomáticos de Deleuze apontando leituras para a complexidade contemporânea e estabelecendo contrapartidas ao cânone cênico estruturalista.

Os modelos teóricos que consubstanciam essa cena passam, portanto, pelos procedimentos de intertextualidade, desconstrução e hibridização. Privilegiando sincronia e geografia de associações - em detrimento do recurso temporalizador -, a écriture contemporânea externa-se na jabberwocky criativa, em associações minimais de imagem, dissonância e antinomia. Nesse sentido, quando Krisinski (1997) aponta preponderância, no contemporâneo, do monólogo em lugar do diálogo, fica claro, pois as 
estruturas monológicas são mais facilmente recambiáveis.

As novas estruturas textuais perpassam o uso do intertexto - enquanto fusão de enunciantes e códigos; a interescritura - onde a mediação tecnológica (rede Internet) possibilita a co-autoria simultânea; o texto síntese ideogramático - na fusão das antinomias; o texto partitura - inscrevendo imagem, deslocamento, sonoridades e a escritura em processo que inscreve temporalidade, incorporando acaso, derivação e simultaneidade. $\mathrm{Na}$ composição do texto espetacular - em inter-relações de autoria, encenação e performance - o hipertexto sígnico estabelece a trama entre o texto lingüístico, o texto storyboard - de imagens, e o texto partitura - geografia dos deslocamentos espaço-temporais.

A nova cena está ancorada em alternâncias de fluxos semióticos e de suportes, instalando o hipersigno teatral, da mutação, da desterritorialização, da pulsação do híbrido: o teatro de Gerald Thomas sustenta-se no signo indicial, das alusões, do rastro, das alternâncias corpo, voz, sentido, imagem.

O contemporâneo contempla o múltiplo, a fusão, a diluição de gêneros: trágico, lírico, épico, dramático; epifania, crueldade e paródia convivem na mesma cena. Thomas e Enrique Diaz alinham, sem medo, os diversos procedimentos cênico-narrativos.

Em relação ao contexto intrínseco da operação teatral, alteram-se, no contemporâneo, as relações clássicas de vozes e textos matriciadores do espetáculo: axiomaticamente estão em jogo três vozes que agenciam texto, lugar e presença - a voz do texto autoral, apriorística, a voz do performer/ator, e a voz do encenador, organizador da mise-en-scène expressiva. No contemporâneo, a voz do encenador, que geralmente é o criador, acumulando autoria, ganha preponderância, priorizando-se o work in progress criativo, na incorporação de intensidades, polifonias, na hibridização dos textos da cultura.

Insemina-se, de outro lado, uma quarta voz expressiva - a voz do receptor-autor - por vias da interatividade em que essa participação cresce, interferindo, mediando e criando textos numa série de manifestações. As novas tecnologias com recursos como Web Art e CD-Rom amplificam essas mediações.

Ao encenador-orquestrador da polifonia cênica, na operação dos fluxos intersemióticos, de partituras de texto, imagem, corporalidades e suportes - e não ao dramaturgo - cabe a guia da cena contemporânea. Encarna, nesse sentido a função do "homem total do teatro" preconizada por Edward Gordon Craig.

Privilegia-se, na nova cena, o criador - em presença - sua voz autoral, em que acumulamse as funções de direção, criação da textualização de processo e linkagem da mise-en-scène. Deslocam-se, na verdade, os procedimentos da performance, em que o criador-atuante partituriza seu corpo, sua emoção, subjetividade, suas relações com a escala fenomenal, com o espaçotempo materiais, para a extensão grupal, a operação cênico-teatral.

Nessa direção, os procedimentos narrativos contemporâneos - na criação de redes interativas - consubstanciam a proposta de uma escritura não seqüencial, corporificando o paradigma da descentralização, formulado por Derrida, para quem o centro é uma função, não uma entidade de realidade. Gesta-se, nessa tessitura hipertextual, a grande "memória interativa”, rizomática, em recursos de proliferação, mediação e subjetivação. Paul Zumthor (1993) destaca o caráter nômade da cultura, que se dissemina pelas oralizaçôes. Nesse sentido, a cultura brasileira é matriz potencial da hibridização de códigos. Por outro lado, a transmissão das "representações", no contemporâneo, opera-se preponderantemente em emissões híbridas configurando as passagens dos códigos verbais puros às emissóes intersemióticas. Nessas passagens contemporâneas, a atuação transita da interpretação (naturalismo) à performance: no Brasil, Beth Coelho é o emblema desse processo com sua presença expressionista e formalista, em seu histrionismo lúgubre. A atuação e as superposiçôes cênicas vão desconstruir a organização 
diacrônica: Gerald Thomas, em sua poética cênica opera um tempo bergsoniano, da duração, do cronos alongado, perpetrando janelas, molduras, que corporificam espacializações mórfico-psíquicas. Os procedimentos de mediação vão ser emblemáticos do contemporâneo, agenciando-se outras relações entre presença, espaço, tempo e representação. À clássica alternância entre presença (real time) e representação (ficcionalidade), impõe-se o par deleuziano memória e atualização.

A relação axiomática da cena corpo-texto-audiência, enquanto rito, totalização, implicando interaçóes ao vivo, é deslocada para eventos intermidiáticos onde a telepresença (on line) espacializa a recepção. $\mathrm{O}$ suporte redimensiona a presença, o texto alça-se a hipertexto, a audiência alcança a dimensão da globalidade. Instaura-se o topos da cena expandida, a cena das vertigens, das simultaneidades, dos paradoxos no incremento do uso do suporte e da mediação nas intervenções com o real. Gera-se o real mediatizado, elevado ao paroxismo pelas novas tecnologias, onde suportes telemáticos, redes de ambientes Web (Internet), CD-Rom e hologramias, simulam outras relações de presença, imagem, virtualidade. As diferenças entre culturas são disseminadas nessas recombinações.

No contemporâneo tecnologizado as alternâncias entre presença e representação são amplificadas à sua hipérbole, ressoando o já clássico paradigma de Derrida da "ausência de presença" $\mathrm{O}$ "aqui-agora" ritualístico é deslocado às montagens disjuntivas propostas pela autoria. A fala viva é mediatizada em sincronias de solilóquios, vozes fantasmáticas, autorais que timbram uma galeria de personas e simultaneidades atemporais.

Numa re-exacerbação da voz autoral (em terceridades estetizadoras) - em detrimento à performance em primeiridade mítica - encenadores simulam seu verfremdugseffekt produzindo hipnotismo, auratização e o re-encantamento da linguagem, na sua dimensão autônoma: Bia Lessa - com seu teatro - cria superfícies de linguagem, Gerald Thomas propõe uma gesamt- kunstwerk polifônica onde matrizes de corporalidades, gestalt imagéticas promovem o discurso onirista. Enrique Diaz enuncia seu topos de releitura, seus deslocamentos cênicos. A mediação redimensiona a presença do performer, seu entorno, seu environment sígnico. Autoria, performance e recepção combinam-se em novos procedimentos de interatividade e sinestesia: Wilson Sukorski performatiza a voz mediatizada em vocoder polissonante; a bailarina Ivani Santana (Duchamp, 1999) simula um environment virtual para sua dança; atuações em CD-ROM redispóem rostos, vozes, textualidades, numa varredura de leit-motiv que promovem outra matriciação sígnica.

O corpo eleva-se à sua dimensão virtual, cria-se o "corpo estendido", pós-humano, laboratorizado em próteses de suporte. As relações da physis são redimensionadas na esfera da tecnologia.

As extensões contemporâneas, promovidas pelos novos suportes, ampliam e prismam a comunicação espaço-temporal, os depósitos memoriais, a interculturalidade, bem como materializam as utopias projetadas nas vanguardas. A tecnologia, pareada aos processos criativos reitera os processos humanos dando morphos e interface aos processos mentais e sensíveis. Nesse sentido, a tarefa do performer contemporâneo é de promover essa extraordinária mediação buscando mímese e auto-poiesis nos novos suportes espelhos.

\section{Poéticas da mestiçagem: latinidade e antropofagias}

No roteiro de uma produção contemporânea, apoiada nos dispositivos e linguagens enumerados, cabe discutir qual o polo de identidade da cultura brasileira, e de que forma se dão as intertextualizações de códigos e fontes referenciais. As geografias, a profusão da natureza, e os modos da colonização em seus diversos agenciamentos delineiam um campo único, quase monódico, de trocas culturais: os trópicos são o espaço da extensão, das forças tectônicas e solares, 
de uma natureza que se introduz no campo da cultura. Herdeira das miscigenaçóes, predominantemente entre as culturas índia, afro e eurocêntricas, funda-se aqui uma "cultura da mestiçagem", do sincretismo, da misturação: um processo, quase de barroquização, como aponta Haroldo de Campos, pela acumulação de conteúdos, que já, pela característica dos colonizadores e pela inclusividade da cultura afro deuse por mecanismos menos sangrentos que na América espanhola. $\mathrm{Na}$ fundação de um modo brasileiro, Oswald de Andrade, no seu Manifesto Antropofágico, de inspiração surrealista, lança o lema: "tupi or not tupi, that is the question..." Propõe o procedimento antropofágico da devoração, da apropriação desautorizada e violenta do corpo "estrangeiro" como único procedimento possível de uma replicação às invasões. Benedito Nunes ${ }^{8}$ alinha, curiosamente, esse mecanismo radical às propostas dadaístas (Picabia, na revista Cannibale) e as irrupçōes da natureza que se insurge à uma suposta cultura civilizatória: "abriu-se de Nietzsche e Freud o caminho que fez do canibalismo o digno de uma síndrome ancestral, ou, para usarmos a linguagem de Oswald de Andrade, uma semáfora da condição humana, fincada no delicado intercâmbio de natureza com a cultura".

Outro aspecto sincrético da cultura se dá pelas religiōes e mitopoéticas: as religiōes afro candomblé, umbanda, quilombo - e os mitos primordiais indígenas são fortemente inclusivos, e são posteriormente figurados com imagens medievais européias e cristãs - da santa, da mãe, dos guerreiros da cruz. Funda-se um modo cultural que incorpora e monta a pluralidade de símbolos. No espaço da festa, das ritualizaçôes, se estabelece o território do mythos que vai dar corporalidade e enlevo ao espetáculo. Estabelecendo arquês de contorno e contato com o grande texto da cultura, a operação mitologizadora é fundante e gera os planos de imanência da cultura.
A cultura brasileira é permeada, portanto, pelas possibilidades do corpo sensível, do corpo andrógino dos deuses, pela erotização, religiosidade onde totem e tabu estão destronados. De um ponto de vista cênico podemos delimitar alguns territórios predominantes e os modos de intertextualização:

1) O território da cena, urbana, universal, de um topos transcultural.

Com os modos de linguagem descritos, os autores-encenadores promovem um grande intertexto entre os signos regionais e o hipertexto da cultura:

Em $K a$ (1998), por exemplo, como diretor, inseminei o texto-anagramático do poeta futurista russo Vélimir Khlébnikov com os rituais do xamanismo brasileiro. Os atores-performers submeteram-se a longos laboratórios rituais para dar vazão a gestos, vocalidades, performances e indumentárias que se intertextualizam com a poética original de Khlébnikov. Paisagens quase antípodas da Rússia gelada e do Brasil tropical são intertextualizadas à luz das mitologias, arqueologias e poéticas delirantes.

2) Espetáculos com demarcada signagem da cultura brasileira intertextualizados pelas linguagens contemporâneas.

Artistas como Antonio Nóbrega (com repertórios do Nordeste brasileiro), o Grupo Lume, de antropologia teatral, que trabalha com a idéia de mimesis cênicas (transpondo, em espetáculo, a fala e o gestual dos povos da floresta amazônica), grupos da Paraíba, estão nesse grupo com o acento puramente regional e a linguagem contemporânea.

3) Eventos mass-media e de cultura globalizada.

Espetáculos de grande público, que se distanciam da pesquisa de linguagem e da busca de intertextualização. Como padrão forte, estão as novelas-teatro da Rede Globo, produzidas no Rio de Janeiro e exportadas para diversos países, inclusive Portugal. 
Por último, é importante destacar o curso de inúmeras produções de ponta, no Brasil, que procuram superar os impasses das trocas culturais e colocam essas matrizes numa rede de câmbios que se distingue dos procedimentos imperativos e doutrinários da globalização.

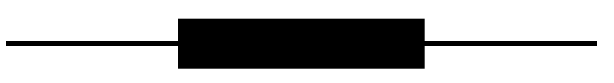

\section{Referências bibliográficas}

AGRA, L. Construtivismo e projeto intersemiótico. São Paulo, PUC, 1997.

CAMPOS, H. Signantia Quasi Coelum - Signância Quase Céu. São Paulo, Ed. Perspectiva/Coleção Signos, 1979.

COHEN, R. Work in Progress na Cena Contemporânea. São Paulo, Ed. Perspectiva, 1998 Performance como Linguagem. São Paulo, Ed. Perspectiva, 1989.

DELEUZE, G. \& GUATTARI, F. Mil platôs capitalismo e esquizofrenia. Rio de Janeiro, Ed. 34, 1996.

FERNANDES, S. Memória e invenção: Gerald Thomas em cena. São Paulo, Ed. Perspectiva, 1996.

FERREIRA, J. P. “Cultura e Memória”. In: Revista USP, 24. São Paulo, 1994/95.

HERKENHOFF, P. \& PEDrOSA, A. (Orgs.) Catálogo da XXIV Bienal de São Paulo: Núcleo Histórico: Antropofagia e História de Canibalismos. São Paulo, 1998.

KRYSINSKI, W. "Estructuras Evolutivas 'Modernas' y 'Postmodernas' del Texto Teatral en el Siglo XX”, In: TORO, F. (ed.). Semiótica y teatro latinoamericano, Buenos Aires, Editorial Galerna/IITCTL, 1990.

LOTMAN, I. Universe of the Mind. (mimeo), 1990.

SUSSEKIND, F. “A imaginação monológica”. Revista USP, 24. São Paulo, 1992.

TURNER, V. "Are there Universals of Performance in Myth, Ritual and Drama?" In: By means of performance - intercultural studies in theatre and ritual. Cambridge University Press, 1990.

ZUMTHOR, P. A Letra e a Voz. São Paulo, Companhia das Letras, 1993. 